\title{
Assessing the usability and efficiency of Design Rationale
}

\author{
Alistair Sutcliffe and Michele Ryan \\ Centre for HCI Design, \\ School of Informatics, City University, Northampton Square, \\ London, EC1V OHB, UK. \\ Email: A.G.Sutcliffe@City.ac.uk
}

\begin{abstract}
Many positive claims have been made about the benefits of Design Rationale (DR). MacLean et al., (1991) argue that an explicit design rationale can be a useful tool in the design process in a variety of ways: from reasoning and reviewing to managing, documenting, and communicating. Design rationale is the notion that goes beyond merely accurate descriptions of artifacts, such as specifications, and articulates and represents the reasons and reasoning process behind the design and specification of artifacts (Moran \& Carroll, 1996). QOC (Questions, Options, Criteria) is a straightforward notation for representing design rationale (MacLean et al., 1991). In this paper we present the results of a study investigating the usability and efficiency of DR/QOC as a design support tool, and provide an analysis of the designers' reflections on the role of DR/QOC in the design process.
\end{abstract}

KEY WORDS Design Rationale, QOC, Design Space Analysis, Empirical study, Design method.

\section{INTRODUCTION}

Design Rationale (DR) in its simplest form is the explicit listing of decisions made during a design process and the reasons why those decisions were made (Jarcyzyk et al., 1992). There are a number of different approaches to DR, for example, MacLean et al., (1989) see DR as a description of the design space, whereas Carroll \& Rosson (1991) see design rationale as a set of psychological claims embodied in an artifact, that is, claims that would have to be true if the artifact is to be usable or claims about psychological consequences for the users of the artifact.

Design Space Analysis is a method for understanding design through analysis, thus a particular artifact is understood in terms of its relationship to plausible alternative designs (MacLean et al., 1991). The basic concepts of Design Space Analysis are expressed using QOC (Questions, Options and Criteria), a semi-formal notation. Design Space Analysis using QOC allows designers to record their choices with supportive criteria or nonfunctional requirements that either justify or detract from a design option. MacLean et al., (1991) believe that if designers used QOC to structure their deliberations, they could improve their reasoning by working with a structure more logically related to the design problem.

There are a number of reported DR empirical studies, e.g. Jorgensen and Aboulafia (1995) found their students were in general able to make good use of DR/QOC and considered the approach very useful for organisation and documentation purposes, but less useful for communication and reflection. 
Karsenty (1996) describes a study evaluating the usefulness of DR documents when re-using a previous design. DR documents describing the solution to a problem in mechanical engineering and the reasons for the design decisions, were made available to the designers. The results showed that $41 \%$ of the designers' questions were answered by the DR documents (e.g. they asked about the reasons for the design decisions, and the different possible choices). However, the DR documents were not sufficient to answer the remaining $59 \%$ of their questions (e.g. they asked questions about the properties of the interfaces and the way the artifact carries out its functionality). Buckingham Shum (1995) reports a study involving pairs of software designers, drawn from professionals and students. He concludes that QOC played both facilitatory and obstructive roles. Olson et al., (1995), researched problem solving during group design and found the structure of activity during ten design meetings was more similar than different.

Our work follows on from these reported studies and we attempt to investigate how DR/QOC can assist the reasoning and decision process, and to assess its usability as a practical method. However, we also wished to explore the utility of QOC for supporting early stages of design (i.e. requirements) and in safety critical domains. In this paper we report the results of a study of industrial designers who used DR/QOC collaboratively as a group to solve a safety critical problem. The study involved: (1) Teaching DR/QOC to a group of software designers, and, (2) Presenting the group with a design problem, their task being to work together and rough-out design choices using QOC.

The paper is organised in four sections. First the experimental study is described. This is followed by a section reporting the data analysis and results. Section four summarises the designers' feedback. The paper concludes with a discussion and ideas for future work.

\section{THE STUDY METHOD}

A group of (approximately) twelve software designers attended a seminar where they were taught DR using the QOC notation. The QOC notation was chosen in preference to other DR representations, e.g. IBIS (Kunz \& Rittel, 1970), and DRL (Lee \& Lai, 1991), because it is relatively simple and the trainer had previous experience of the technique. All of the designers were employed by the same company and many of them had worked together previously.

An example of DR using QOC was illustrated by considering the various options for designing house shelving. Options included 'open shelving' or 'glass fronted shelving', and criteria included 'items being accessible' and 'safe from climbing kids'. During the seminar the designers asked questions about QOC and how it could be used. Illustrating QOC and answering questions took approximately twenty minutes. The group were then presented with a 160 word narrative of a safety critical problem. They were asked to use QOC to rough-out the choices involved in designing a safety device for handling a gas jet, which must not lead to explosions. This task had initially been reviewed by a manager who considered it to be a realistic problem, within the designers' domain, but unlikely to be one they would have solved previously. The group were given fifteen minutes to work on the problem. One member of the group acted as a facilitator and wrote the options and criteria on a whiteboard, while the rest of group called out their ideas. This part of the seminar was audio taped and then transcribed.

The data obtained from the study consists of: (1) A transcript of the group discussion that took place while constructing the QOC, and, (2) A copy of the QOC diagram created by the group.

\section{DATA ANALYSIS AND RESULTS}

The QOC diagram produced by the group is shown in Figure 1. The numbers indicate the order in which the options, criteria and links were identified, showing a rather irregular development process. This supports Buckingham Shum's findings that externalising ideas as structured argumentation is not a smooth top down process (Buckingham Shum, 1995). Due to time constraints the criterion 'reliable' remained unconnected to options. 


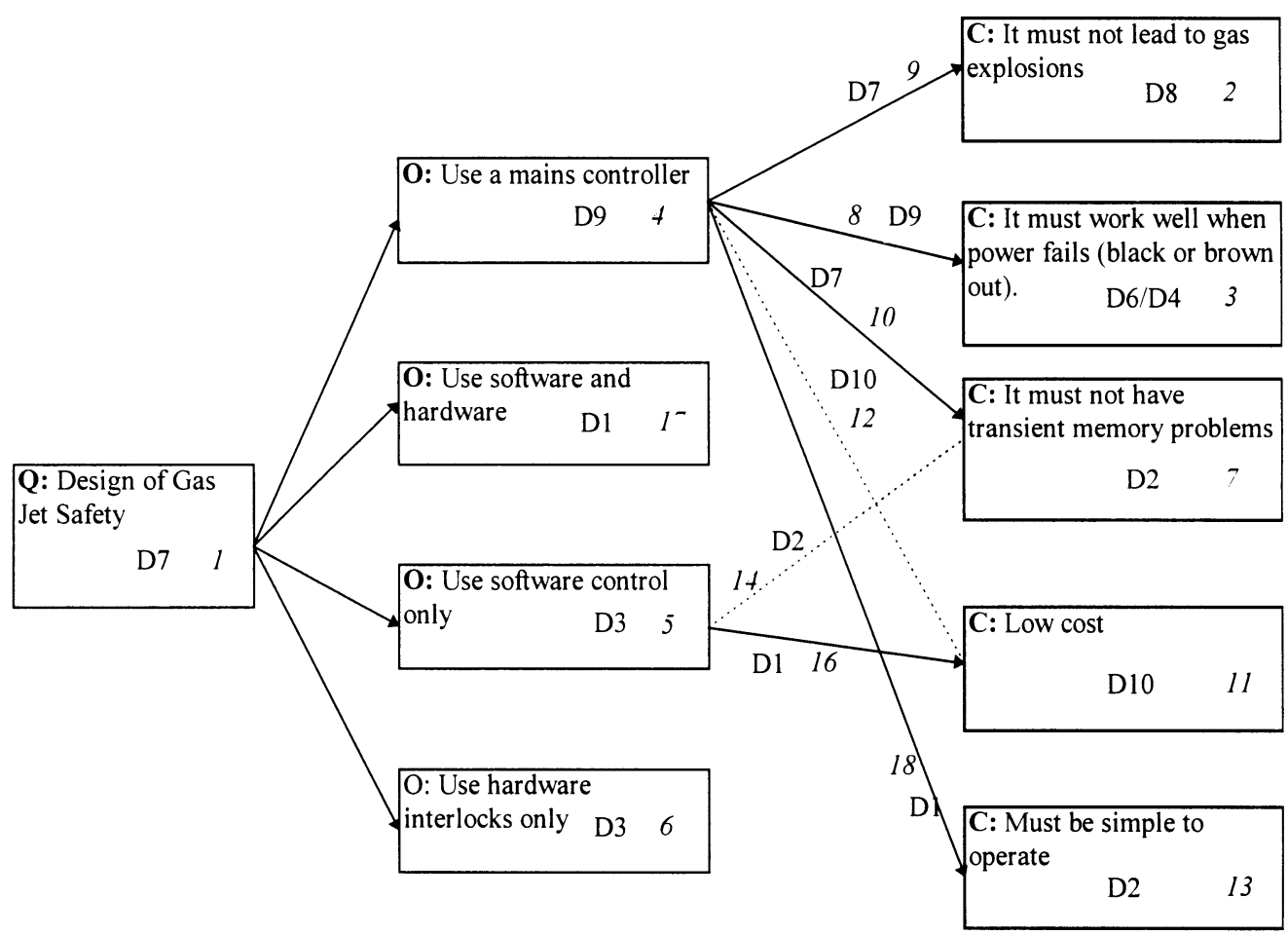

Figure 1. A QOC diagram for the design of Gas Jet Safety.

Dotted lines represent negative links, full lines positive links. Numbers indicate the order in which the items were identified. ' $\mathrm{D}$ ' numbers indicate designer contributions.

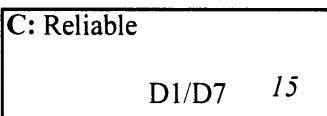

The transcript was analysed three times. The first pass involved analysing the content topics (see 3.1), the second pass involved analysing how the designers applied and used the QOC technique (see 3.2), and the third pass analysed the designers' individual contributions (see 3.3).

\subsection{Content Analysis - first pass}

Speech segments in the transcripts were associated with topic categories. These are shown in Figure 2 and a timeline graph of topics discussed is shown in Figure 3.

\begin{tabular}{|l|l|}
\hline Content cat. & Description \\
\hline $\begin{array}{l}\text { Problem } \\
\text { requirements } \\
(2 \%)\end{array}$ & $\begin{array}{l}\text { Statements in the transcripts } \\
\text { identifying the problem being } \\
\text { addressed. }\end{array}$ \\
\hline $\begin{array}{l}\text { Non-functional } \\
\text { requirements }\end{array}$ & $\begin{array}{l}\text { Statements referring to non- } \\
\text { functional requirements of the } \\
\text { system (e.g. cost, reliability, } \\
\text { safety, must be easy to } \\
\text { understand). }\end{array}$ \\
\hline QOC technique & $\begin{array}{l}\text { Statements that refer to the QOC } \\
\text { technique/notation (e.g. whether } \\
\text { an item should be classified as an } \\
\text { option or a criterion). }\end{array}$ \\
\hline
\end{tabular}




\begin{tabular}{|l|l|}
\hline $\begin{array}{l}\text { Design } \\
\text { alternatives }\end{array}$ & $\begin{array}{l}\text { Statements identifying alternative } \\
\text { designs (e.g. implement the } \\
\text { solution in hardware or software, } \\
\text { or a mixture of both). Includes } \\
\text { descriptions and comparison of } \\
\text { design alternatives. }\end{array}$ \\
\hline $\begin{array}{l}\text { Other } \\
(8 \%)\end{array}$ & $\begin{array}{l}\text { Statements that do not fall into } \\
\text { any of the above categories. }\end{array}$ \\
\hline $\begin{array}{l}\text { Design } \\
\text { requirements }\end{array}$ & $\begin{array}{l}\text { Statements referring to the } \\
\text { requirements of the design (e.g. } \\
\text { whether the solution had to be } \\
\text { implemented in hardware or } \\
\text { software). }\end{array}$ \\
$(2 \%)$ & $\begin{array}{l}\text { References to the knowledge of } \\
\text { users who will use the system }\end{array}$ \\
\hline $\begin{array}{l}\text { Users } \\
(2 \%)\end{array}$ & $\begin{array}{l}\text { References to how long it may } \\
\text { take to implement a solution. }\end{array}$ \\
\hline $\begin{array}{l}\text { Volume } \\
\text { work } \\
(2 \%)\end{array}$ & \\
\hline
\end{tabular}

Figure 2. Topic categories discussed by the designers.

The topic the designers talked about most was the QOC technique (31\% of speech segments). They experienced a number of difficulties with the method, (e.g. they often did not know whether to classify an item as an option or a criterion). Also, on a number of occasions the notation did not naturally reflect their thoughts. See section 3.2.2 for further analysis.

The next most discussed topic was non-functional requirements $(29 \%$ of speech segments). These include: safety, cost (product and development), simple operation, easy to understand, reliability, robustness, prevention of gas explosions and handling power failure. Most of the requirements identified by the designers, which were represented as Criteria, are non-functional requirements. Discussing design alternatives was common ( $24 \%$ of speech segments), Options in the QOC diagram show the alternatives discussed. The designers made few references to users ( $2 \%$ of speech segments), and no reference to user interface design.

Design and problem requirements were only mentioned briefly ( $2 \%$ of speech segments for each category), and due to the time constraint, the discussion did not consider system functionality (i.e. the components of the system and how the system requirements would be fulfilled). Work required to implement a solution was referred to $(2 \%$ of speech segments). Other statements not categorised accounted for $8 \%$ of speech segments. These consisted of interactions that did not refer to any specific topic (e.g. 'Nigel you were about to say something..').

Non-functional requirements, the QOC technique, and design alternatives were discussed throughout the session (see Figure 3).

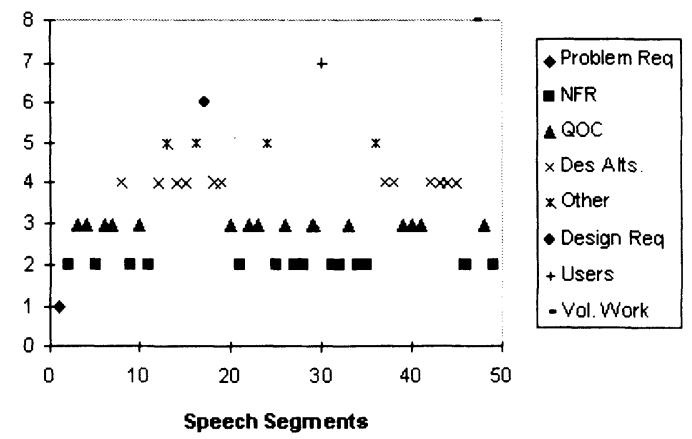

Figure 3. Timeline graph of topics discussed.

\subsection{Using QOC - second pass}

Speech segments in the transcript were classified into the following 2 categories:

1. Applying QOC to the problem - Utterances that specify questions, options and criteria and construct negative and positive links. Also, reasoning about the options and criteria chosen.

2. Reflections on the QOC technique - Utterances about QOC (e.g. statements expressing difficulty in using the notation). In fact, this essentially involved de-composing the content analysis 'QOC Technique' category in Figure 2.

The purpose of this analysis was to separate statements which simply involved the designers using the technique in a straightforward way, from statements expressing the designers' reflections about the method, (e.g. where the designers were puzzled or confused by the technique).

\subsubsection{Applying $Q O C$ to the problem}

$70 \%$ of speech utterances in the transcripts involved the designers constructing questions, options and 
linking criteria. Of these, $3 \%$ of speech statements referred to Questions, 33\% to Options, $40 \%$ to Criteria and $24 \%$ to linking Options to Criteria.

On the whole the designers did reason effectively about their choice of options and criteria, but they did not reason in any great depth. We investigated this by tracing their reasoning and decision process, to explain how each QOC item was produced (see Figure 4).

\begin{tabular}{|c|c|}
\hline QOC Item & $\begin{array}{l}\text { Prompted by narrative / } \\
\text { Designers' reasoning. }\end{array}$ \\
\hline $\begin{array}{l}\text { Q: The design of the } \\
\text { gas jet safety. }\end{array}$ & Problem narrative. \\
\hline $\begin{array}{l}\text { C: It must not lead to } \\
\text { gas explosions. }\end{array}$ & Problem narrative. \\
\hline $\begin{array}{l}\text { O: Hardware or } \\
\text { software. }\end{array}$ & $\begin{array}{l}\text { Reasoning - considering how } \\
\text { the solution should be } \\
\text { implemented prompted } \\
\text { hardware/software options. }\end{array}$ \\
\hline $\begin{array}{l}\text { C: It must handle power } \\
\text { failure. }\end{array}$ & Just stated by designers. \\
\hline $\begin{array}{l}\text { C: It must work well } \\
\text { when power fails (black } \\
\text { or brown out). }\end{array}$ & $\begin{array}{l}\text { Reasoning - a specialisation } \\
\text { of criterion, 'It must handle } \\
\text { power failure'. }\end{array}$ \\
\hline O: Mains controller. & $\begin{array}{l}\text { Reasoning - proposed to } \\
\text { prevent black/brown out (as } \\
\text { specified in the criterion, 'It } \\
\text { must work well when power } \\
\text { fails'). }\end{array}$ \\
\hline $\begin{array}{l}\text { C: It must not have } \\
\text { transient memory } \\
\text { problems. }\end{array}$ & $\begin{array}{l}\text { Reasoning - transient memory } \\
\text { problems may result if the } \\
\text { solution is implemented in } \\
\text { software. }\end{array}$ \\
\hline $\begin{array}{l}\text { L: Negative link from } \\
\text { transient memory to } \\
\text { software. }\end{array}$ & As above. \\
\hline $\begin{array}{l}\text { L: Positive link from } \\
\text { mains controller }\end{array}$ & $\begin{array}{l}\text { Reasoning - because an } \\
\text { instrument which does not } \\
\text { have black or brown outs is } \\
\text { safe. }\end{array}$ \\
\hline C: Low cost & $\begin{array}{l}\text { Reasoning - because it's a } \\
\text { solution for the 3rd world (as } \\
\text { per problem narrative). }\end{array}$ \\
\hline C: Robust & Just stated by designers. \\
\hline C: Reliable & Just stated by designers. \\
\hline $\begin{array}{l}\mathrm{O} \text { : Mixture of hardware } \\
\text { and software. }\end{array}$ & $\begin{array}{l}\text { Reasoning - because the } \\
\text { options hardware only and } \\
\text { software only were identified, } \\
\text { so an option is to have both } \\
\text { together. }\end{array}$ \\
\hline
\end{tabular}

\begin{tabular}{|l|l|}
\hline L: Software to low cost & $\begin{array}{l}\text { Reasoning - because software } \\
\text { is cheaper than hardware. } \\
\text { Some designers disagreed } \\
\text { with this. }\end{array}$ \\
\hline $\begin{array}{l}\text { L: Positive link from } \\
\text { simple operation to } \\
\text { mains controller }\end{array}$ & $\begin{array}{l}\text { Reasoning - because it will be } \\
\text { a 'dead simple' operation. }\end{array}$ \\
\hline $\begin{array}{l}\text { L: Negative link from } \\
\text { robust to mains } \\
\text { controller }\end{array}$ & $\begin{array}{l}\text { Reasoning - because } \\
\text { compared to other things. it } \\
\text { was not considered } \\
\text { particularly robust. }\end{array}$ \\
\hline
\end{tabular}

Figure 4. Reasoning in the creation of (Q)uestions. (O)ptions, (C)riteria and (L)inks.

On a number of occasions the designers did not appear satisfied with the populated QOC diagram. For example, one designer considered that the criterion 'It must not have transient memory problems', was 'not that obvious'. Another designer considered the software/hardware options had produced a 'woolly' statement, because one could then ask, "which is software and which is hardware ... we're talking about extremes'. Further on, the designers claim it's a 'bit of a cop out saying use software .. and hardware .. it's a bit general'.

\subsubsection{Reflections on the QOC technique}

$30 \%$ of transcript speech segments reflected the designers' concern in understanding the semantics of the QOC technique. These include the designers having difficulty specifying whether an item is an option or a criterion (e.g. 'What you are saying it's an option rather than a criterion), and feeling constrained by the notation, (e.g. 'You have to express that in a positive way').

The following observations summarise the designers' experience of using QOC.

- Early on they encountered problems working with QOC. Finding options to questions was difficult as one engineer noted, 'whatever option you put down, you do not have anything that's a possibility for the design of gas jet safety'.

- They experienced difficulty when attempting to classify ideas. The notation caused confusion between what might be an option and what might be a criterion (e.g. a discussion took place around whether, 'handling power failure', was an option or a criterion). The method distracted the 
designers. Discussion within the group often focused on how to classify an issue rather than identifying the issues needed to solve the problem.

- The notation was constraining as the designers felt they had to express criteria in a positive way.

- Understanding the meaning of options was a problem. The group were not satisfied that options were really solutions to questions, as one designer pointed out the option, 'use a mains condition', is 'not really a sort of answer in itself. ... it's use of mains conditioner, but that's not a design for a gas jet safety'.

- The designers' expression of ideas was difficult (e.g. they didn't think they could represent, 'if it's going to take a year of software to do, it might not be worth doing it for the amount of the size of the contract'). Finally, they decided on 'low product' and 'low development costs' as criteria, but they had to change their natural way of thinking.

\subsection{Individual Contributions - third pass}

The facilitator D7 contributed most to the discussion, followed by D8, while D6 contributed least.

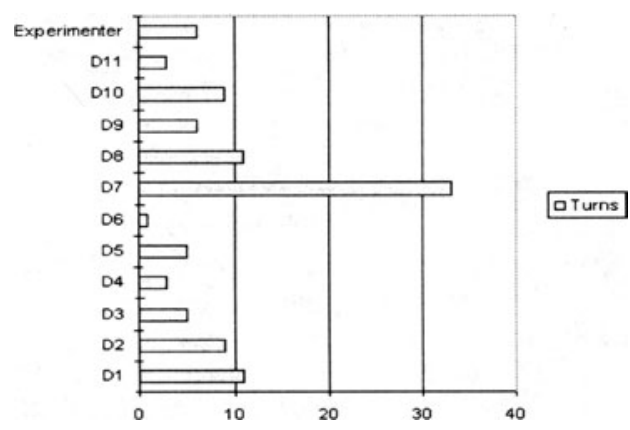

Figure 5. Designers' speech turns frequency.

The facilitator D7 consistently talked throughout the discussion. He did not dominate the group discussion, rather he held it together, where necessary passing an undecided point to the group for their opinion, encouraging speakers to articulate their thoughts and accepting overall agreement.

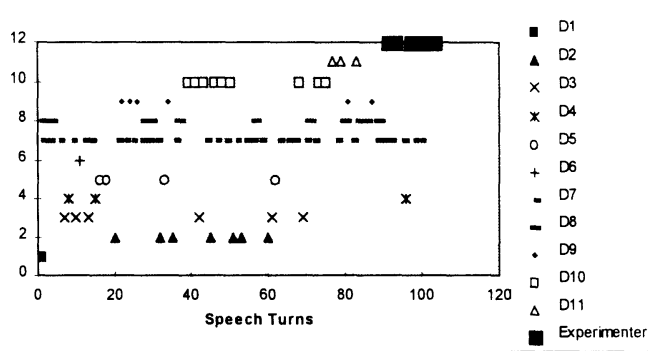

Figure 6. Designers' speech turns shown over time.

The QOC method facilitated participation. Most of the designers made contributions that were included in the final QOC, with exception to designers D5 and D6. See Figures 1 and 7.

\begin{tabular}{|l|l|l|l|l|l|l|l|l|l|l|}
\hline Designer & 1 & 2 & 3 & 4 & 5 & 6 & 7 & 8 & 9 & 10 \\
\hline Contribution & 4 & 3 & 2 & 1 & 0 & 0 & 4 & 1 & 2 & 2 \\
\hline
\end{tabular}

Figure 7. Designer QOC Contribution Frequency.

\section{DESIGNERS' FEEDBACK}

Only half of the designers who attended the seminar gave feedback anonymously at the end. They were asked to provide feedback on QOC using a Likert scale. Figure 8 shows their ratings on a 7 point scale, where 7 indicates that the condition has been fully satisfied and 1 indicates the reverse.

\begin{tabular}{|c|c|c|c|c|c|c|c|}
\hline Condition & \begin{tabular}{l|}
$\mathbf{D}$ \\
$\mathbf{1}$
\end{tabular} & \begin{tabular}{l|}
$\mathrm{D}$ \\
2 \\
\end{tabular} & $\begin{array}{l}\mathbf{D} \\
\mathbf{3} \\
\end{array}$ & \begin{tabular}{|l|}
$D$ \\
4 \\
\end{tabular} & \begin{tabular}{l|} 
D \\
5
\end{tabular} & \begin{tabular}{l|}
$\mathrm{D}$ \\
6 \\
\end{tabular} & Av. \\
\hline $\begin{array}{l}\text { 1. The extent the QOC } \\
\text { diagram included relevant } \\
\text { options and criteria. }\end{array}$ & 1 & 5 & 2 & 2 & 2 & 1 & 2.2 \\
\hline $\begin{array}{l}\text { 2. How accurately the } \\
\text { QOC diagram represented } \\
\text { the options and criteria } \\
\text { (regardless of how correct } \\
\text { they were). }\end{array}$ & 4 & 2 & 3 & 4 & 2 & 2 & 2.5 \\
\hline $\begin{array}{l}\text { 3. How clearly the QOC } \\
\text { diagram represented the } \\
\text { options and criteria. }\end{array}$ & 3 & 5 & 2 & 5 & 2 & 1 & 3 \\
\hline $\begin{array}{l}\text { 4. The correctness of the } \\
\text { options/criteria in the } \\
\text { QOC. }\end{array}$ & 2 & 2 & 3 & 4 & 2 & 3 & 3 \\
\hline
\end{tabular}




\begin{tabular}{|l|l|l|l|l|l|l|l|}
\hline $\begin{array}{l}\text { 5. How easy it is to learn } \\
\text { the QOC notation. }\end{array}$ & 6 & 6 & 2 & 6 & 5 & 5 & 5 \\
\hline $\begin{array}{l}\text { 6. How useful QOC is for } \\
\text { representing design issues } \\
\text { in your field. }\end{array}$ & 4 & 3 & 2 & 5 & 1 & 3 & 3 \\
\hline
\end{tabular}

Figure 8. Designers' initial feedback (1 low, 7 high).

Most of the designers considered that the QOC diagram they produced in the experiment did not include relevant options and criteria for this problem (see condition 1, Figure 8). This may reflect the experimental time constraint or their opinion that QOC was not a suitable way of representing the relevant issues for the problem. This is supported by their general low rating of the correctness of the options and criteria (see condition 4, Figure 8).

\subsection{Feedback after 8 months}

Eight months after the seminar the designers were asked to give further feedback on their use of QOC. None of the them had used QOC at all since the seminar eight months previously. However, there had been no management impetus to do so. Five of the seven designers gave lack of opportunity as the reason for not using QOC. The other two cited that QOC was inappropriate. Most of the designers' work involves producing new versions of existing software packages or adding new features. They explained that this does not often lend itself to producing new designs; they simply reuse existing designs. This may reflect the need to introduce DR via a library of rationales to promote a critical mass of useful documentation. Alternatively, they may have been an anti-method culture, but the designers did employ other design methods. Seven of the designers used methods from the following list; Object Oriented Design, Object Oriented Diagrams, OMT, Coad/Yourdon and State Tables. Only one of the designers reported that he did not use any other design notation or method.

\subsubsection{Benefits of using $Q O C$}

Three of the seven software designers considered that there were no advantages in using QOC. Advantages given by the rest of the group follow:

- Helps to record our thought processes.

- Useful for small projects or sub-projects but not for large projects.
- QOC may be useful if starting a new project, but not for an existing project.

- Anything is an improvement on ad-hoc techniques.

\subsubsection{Disadvantages of using $Q O C$}

Six of the seven designers considered that QOC was not very useful for representing design issues in their field. Two of the designers who did not cite any benefits, did not cite any disadvantages either. Other disadvantages included:

- Even very small areas of design generate massive QOC diagrams. Unwieldy for large problems.

- Learning curve required albeit short.

- Seems too theoretical.

- If you do not know what the questions are, it is not possible to design relevant criteria.

None of the designers thought they would use the technique again. They gave the following reasons.

- Too time consuming for the benefits.

- Projects are already satisfied by using existing tools. Quite risky to use new tools.

- Most of their work involves using existing designs

- No CASE support available. The various notations/methods used in the past have needed good CASE tools to cope with real problems.

\section{DISCUSSION}

Generally the QOC categories did not give significant problems. However, the designers did have difficulty in decomposition, but this could be because the trainer did not explain this aspect clearly. The confusion between options and criteria highlights the problem of how QOC elements change during the analytical process (i.e. the solution to a criteria becomes a lower level option). QOC does not guide decomposition as clearly as some top down methods (e.g. DeMarco, 1978).

The QOC notation tended to keep the focus on high level options (software vs. hardware) which seemed to inhibit detailed reasoning. The QOC framework may encourage a leap from questions to possible solutions, thereby missing the reasoning process in between. However, QOC did function effectively for trade-off analysis as illustrated in the final QOC diagram. This 
suggests the need to encourage QOC decomposition and annotations on diagrams for impact consequences. Using QOC with some other modeling technique may help more detailed reasoning.

Any new notation needs considerable training even if it is relatively simple. Our study showed that the designers spent much of their time discussing the method, rather than focusing on the problem, but this was probably an artifact of the method's novelty. The lack of long term take up is probably due to lack of management impetus, a factor necessary for adoption of structured methods, and the application domain which needed a critical mass of QOCs. The lack of CASE tools could have discouraged using the method.

QOC is supposed to be a general representation, so it should be applicable to any trade-off problem with design options and criteria. QOC may be sensitive to the scale of the problem, indeed previous reports have used it for small scale user interface design issues (MacLean et al, 1991) so our findings suggest that QOC may not scale to problems which are more open ended and complex in the requirements and early scope stages of design. The users were novices, no doubt we may have got better results with QOC experts, but the point of the study (and QOC) is to test a light weight, supposedly easily learned notation in industry. We found it didn't always work, as have others (Buckingham Shum, 1995).

Finally, the study did show evidence that QOC can help structure requirements agreeing with other studies (e.g. Sutcliffe, 1995) which demonstrated that DR is partially successful for requirements analysis. However, it also demonstrated that in-depth training is necessary for even a simple method and that other specification languages are necessary for use with DR to support more detailed reasoning.

\section{Acknowledgments}

This research was supported by the SERC/DTI Safety Critical programme in project GR H/89944 DATUM. Many thanks to Dr Gordon Rugg for collecting the data and to Liz Bromley for transcribing the tape.

\section{REFERENCES}

Buckingham Shum S. Analyzing the Usability of a Design Rationale Notation, 1995. In T. P. Moran \& J. M. Carroll (Eds.), Design Rationale: Concepts, techniques, and use. Lawrence Erlbaum, 1996.

Carroll M J and Rosson B M. Deliberated Evolution: Stalking the View Matcher in Design Space, 1991. In T. P. Moran \& J. M. Carroll (Eds.), Design Rationale: Concepts, techniques, and use. Lawrence Erlbaum Associates, 1996.

DeMarco T. Structured Analysis and System Specification. New York: Yourdon Press, 1978.

Jarczyk A, Loffler F, \& Shipman M. Design Rationale for Software Engineers: A survey. IEEE, 1992.

Jorgensen A H and Aboulafia A. Perceptions of Design Rationale. Human-Computer Interaction, Interact, Eds. K Nordby et al, pp. 61-66, 1995.

Karsenty L. An Empirical Evaluation of Design Rationale Documents. In Proceedings of CHI-96, April 13-18th, Ed. M. J. Tauber, 1996.

Kunz W and Rittel H W J. Issues as elements of information systems (Working Paper No. 131). Berkeley: University of California, Berkeley, Center for Planning and Development Research, 1970.

Lee $\mathrm{J}$ and Lai K-Y. What's in Design Rationale?, 1991. In T. P. Moran \& J. M. Carroll (Eds.), Design Rationale: Concepts, techniques, and use. Lawrence Erlbaum Associates, 1996.

MacLean A, Young R \& Moran T. Design Rationale: The Argument Behind The Artifact, CHI, 1989.

MacLean A, Bellotti V, and Moran T. Questions, Options, and Criteria: Elements of design space analysis, 1991. In T P Moran \& J M Carroll (Eds.), Design Rationale: Concepts, techniques, and use. Lawrence Erlbaum Associates, 1996.

Moran $\mathrm{T}$ P and Carroll $\mathrm{J}$ M. Design Rationale: Concepts, techniques, and use. Lawrence Erlbaum Associates, 1996.

Olson M G, Olson S J, Storrosten M, Carter M, Herbsleb J, and Rueter H. The Structure Of Activity During Design Meetings, 1995. In T. P. Moran \& J. M. Carroll (Eds.), Design Rationale: Concepts, techniques, and use. Lawrence Erlbaum, 1996.

Sutcliffe A. Requirements Rationales: Integrating Approaches to Requirement Analysis. Symposium on Designing Interactive Systems: Processes, Practices, Methods \& Techniques Conference Proceedings. Eds. G. M. Olson \& S. Schuon, 1995. 